\title{
Carotid Endarterectomy Without Indwelling Shunts and Intraoperative Electrophysiologic Monitoring
}

\author{
Kesava Reddy, Michael West and Brian Anderson
}

\begin{abstract}
Although carotid endarterectomy is a common surgical procedure in North America, controversies exist regarding the type of anesthesia, the use of indwelling shunts and the need for intraoperative cerebral monitoring. We present a prospective study of 100 carotid endarterectomies performed over a three year period by a single surgeon without the use of indwelling shunts, patch grafts, or EEG monitoring. The combined stroke and mortality rate was $1 \%$. Our results confirm those of other authors; that indwelling shunts and EEG monitoring are not absolutely essential for a satisfactory outcome in carotid endarterectomies.
\end{abstract}

\begin{abstract}
RÉSUMÉ: Endartérectomie carotidienne sans mise en place de dérivation à demeure et sans monitorage électrophysiologique peropératoire Quoique l'endartérectomie carotidienne soit une intervention chirurgicale courante en Amérique du nord, le type d'anesthésie, l'utilisation de dérivation à demeure et la nécessité du monitorage cérébral peropératoire demeurent des procédures controversées. Nous présentons une étude prospective de 100 endartérectomies carotidiennes effectuées sur une période de trois ans par le même chirurgien sans mise en place de dérivation à demeure, de greffe ou de monitorage EEG. Le taux combiné d'ictus et de mortalité a été de 1\%. Nos résultats confirment ceux d'autres auteurs à savoir que les dérivations à demeure et le monitorage EEG ne sont pas absolument essentiels pour obtenir un résultat satisfaisant dans les endartérectomies carotidiennes.
\end{abstract}

Can. J. Neurol. Sci. 1987; 14:131-135

Extracranial carotid artery surgery was introduced in 1954.' The first carotid endarterectomy was reported by Cooley in $1956 .{ }^{2}$ Since then there has been a progressive rise in the popularity of carotid endarterectomy. It has been estimated that there has been a $467 \%$ increase in the number of these procedures performed in the United States between 1971 and $1982 .^{3}$ Controversy has grown with the popularity of this procedure, as evidenced by the numerous publications on this subject. Foremost amongst the controversies have been the use of intraoperative shunts, ${ }^{4-14}$ electrophysiologic monitoring ${ }^{15-22}$ and patch grafts. ${ }^{23,24}$ Results of the present series of endarterectomies, performed without these adjuncts, support the conclusion of others ${ }^{5,7-9,12,14}$ that for a successful outcome, these measures are not absolutely essential.

\section{Materials And Methods}

\section{Patient Data}

This is a prospective study of 100 consecutive carotid endarterectomies in a total of 89 patients performed in St. Boniface General Hospital over a three year period by a single surgeon (M.W.). Fifty-four patients were male and 35 female. Mean age was 64 years for males and 66 years for females. Fifty-one of the procedures were left-sided and 49 right-sided. Forty-eight patients had carotid bruits appropriate to the side of their symptoms. Twenty-two of these 48 patients had an associated contralateral bruit. Various risk factors in our patients are depicted in Figure 1. All the patients were assigned to Groups I to IV, based on preoperative risk factors, according to the Mayo Clinic Guidelines. ${ }^{25}$ The patient distribution amongst these groups is shown in Table 1. Sixty percent of the patients were in Groups III and IV. The mean age, sex distribution, and the risk factors for localized carotid disease in the series is similar to that in other reported series.

\section{Indications for Surgery}

Our main indications for carotid endarterectomy were transient cerebral and retinal ischemic episodes, reversible isch-

From the Section of Neurosurgery, Department of Surgery (Drs. Reddy and West) and the Section of Neurology, Department of Medicine, University of Manitoba, Winnipeg, Manitoba (Dr. Anderson)

Received August 26, 1986. Accepted in final form February 21, 1987

Reprint requests to: Dr. Michael West, 307, 400 Tache Avenue, Winnipeg. Manitoba, Canada R2H 3C3 


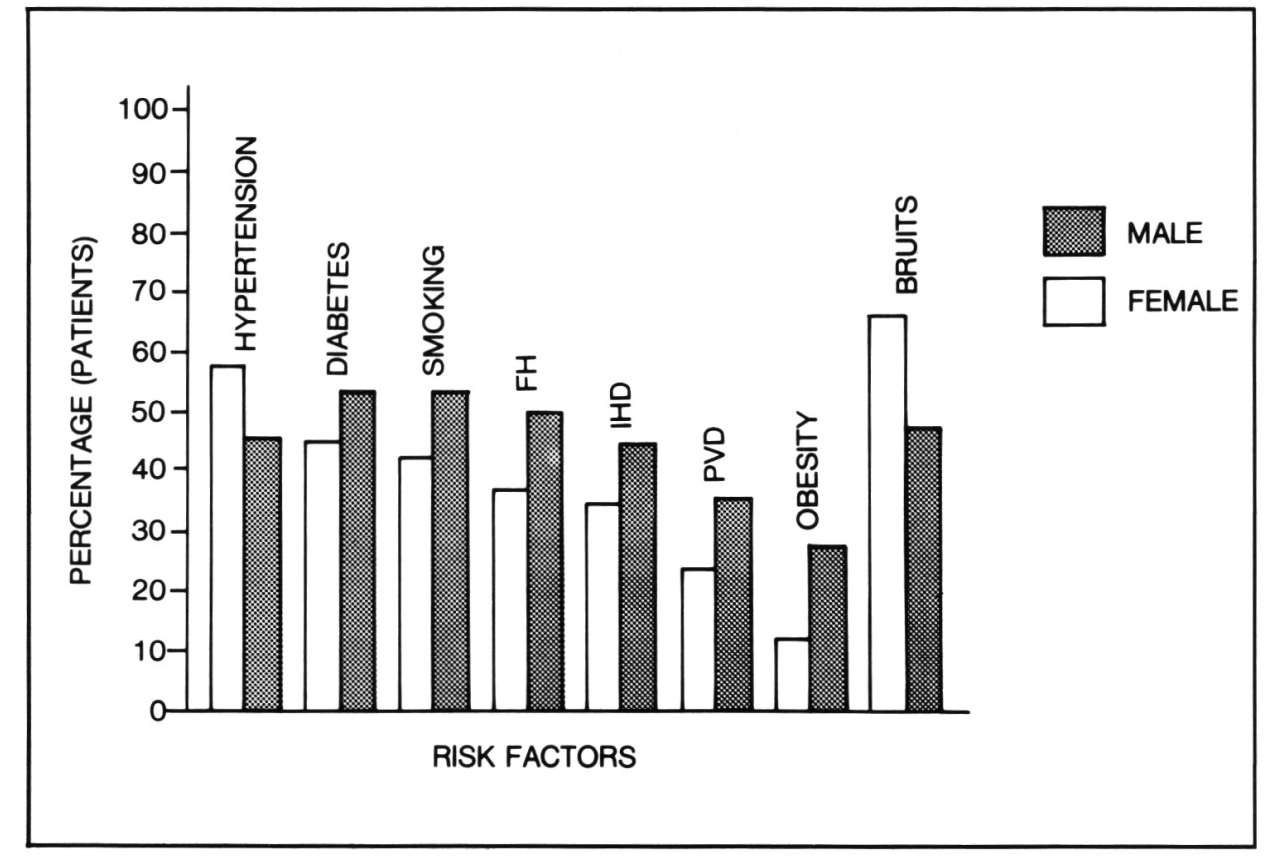

Figure I - Preoperative risk factors amongst our patients:

$F H=$ Family history of stroke or ischemic heart disease

$P V D=$ Peripheral vascular disease

$I H D=I$ schemic heart disease

\begin{tabular}{cc}
\hline Table 1: Clinical Grouping (Mayo Clinic Criteria*) \\
\hline \hline Group & $\begin{array}{c}\text { Percentage } \\
\text { (of 89 patients) }\end{array}$ \\
\cline { 2 - 2 } I & $36 \%$ \\
II & $4 \%$ \\
III & $45 \%$ \\
IV & $15 \%$ \\
\hline
\end{tabular}

*GROUP I - Neurologically stable patients with no medical or angiographic risks

GROUP II - Neurologically stable patients with angiographic risks alone

GROUP III - Neurologically stable patients with major medical risks, but no angiographic risks

GROUP IV - Neurologically unstable patients with or without the other risks

emic neurologic deficits, and minor strokes (Table 2). The 5 procedures performed for asymptomatic lesions were for lesions with over $70 \%$ stenosis and all these patients had a symptomatic contralateral lesion. Apart from this small group, asymptomatic patients were excluded as surgical candidates, as were the patients with vertebrobasilar symptoms alone, patients with diffuse cerebrovascular disease, and patients with complete internal carotid occlusion.

\section{Angiography}

All the patients were studied by transfemoral arch aortography and bilateral selective carotid angiography. The angiographic findings have been grouped according to the degree of stenosis and the presence or absence of ulceration (Table 3), as ulceration has been shown to increase the risk of embolic stroke. ${ }^{26}$ Patients with contralateral occlusion or severe stenosis have been grouped separately, as some authors identify this combination as an indication for the use of intraoperative shunts ${ }^{13}$ on the premise that these patients are at a higher risk for stroke.

\begin{tabular}{|c|c|}
\hline Indication & $\begin{array}{c}\text { Percentage of } \\
\text { Total Procedures } \\
\end{array}$ \\
\hline $\begin{array}{l}\text { Transient Ischaemic Attacks } \\
\& \& \\
\text { Amaurosis fugax }\end{array}$ & $70 \%$ \\
\hline $\begin{array}{l}\text { Reversible Ischaemic } \\
\text { Neurologic Deficit }\end{array}$ & $11 \%$ \\
\hline Minor/Recovered Stroke & $14 \%$ \\
\hline Asymptomatic & $5 \%$ \\
\hline & $\begin{array}{c}\text { Percentage } \\
\text { (of } 100 \text { Procedures) }\end{array}$ \\
\hline $\begin{array}{c}\text { Ipsilateral stenosis } \\
<50 \% \\
50-75 \% \\
75-99 \%\end{array}$ & $\begin{array}{r}2 \\
19 \\
64\end{array}$ \\
\hline $\begin{array}{l}\text { Stenosis and Contralateral } \\
\text { occlusion } />75 \% \text { stenosis }\end{array}$ & 3 \\
\hline $\begin{array}{l}\text { Ulceration } \\
\quad<50 \% \text { narrowing } \\
>50 \% \text { narrowing }\end{array}$ & $\begin{array}{l}4 \\
8\end{array}$ \\
\hline
\end{tabular}

\section{Perioperative Management}

Mild hypervolemic hemodilution was used for all but six of the procedures by transfusing $500 \mathrm{cc}$. of $5 \%$ Albumin over 8-9 hours prior to surgery with a view to improving cerebral perfusion intraoperatively and to prevent potential hypotension during induction of anesthesia. The mean drop in hemoglobin and hematocrit was $.20 \mathrm{gm} / \mathrm{litre}$ and .056 respectively.

General anaesthesia and standard operative technique were employed with minor variations. Prior to arteriotomy, 0.5 to $1 \mathrm{cc}$. of $0.1 \%$ Xylocaine was injected into the adventitial tissue 
at the bifurcation to obviate intraoperative and early postoperative fluctuations in blood pressure. A bolus injection of 10,000 units of Heparin was given intravenously 5 minutes prior to the arteriotomy. The endarterectomy was accomplished using Loupe magnification without indwelling shunts, vein patch grafts or electrophysiologic monitoring. Normotension or mild hypertension (10-20 Torr above the preoperative mean blood pressure) along with normocarbia, was maintained throughout the procedure. Half the reversal dose of protamine was used immediately after closure of the arteriotomy. The mean clamp time was $28 \mathrm{~min}$. Mean surgical time was $119 \mathrm{~min}$.

Postoperatively the mean arterial pressure was maintained between 80-100 Torr using intravenous diazoxide, nitroprusside or hydralizine to control hypertension, and volume loading or alpha-agonists for hypotension. During the postoperative period, regular evaluations were performed to detect any fresh neurologic deficits and possible regional complications. Patients were discharged within the first postoperative week unless complications had been noted. All patients were advised to take $1300 \mathrm{mg}$ of coated Aspirin daily indefinitely. Routine postoperative angiography was not performed in view of the high risk: benefit ratio. Mean follow-up period was 46 weeks. Three patients were lost to follow-up.

\section{RESULTS}

The results were analyzed in terms of minor and major morbidity, major morbidity being defined as that interfering with active daily life. Minor morbidity included complications that had resolved within the follow-up period for each patient, and had not interfered with active daily life (Table 4). There was no mortality in this series. One patient was hemiplegic as a result of a technical error. This procedure was prolonged due to a difficult dissection of a high bifurcation, and an immediate postoperative angiogram revealed an intimal flap. The patient was returned to the operating room and the flap was tacked down immediately. The presumed etiology of the ensuing hemiplegia was embolic and we feel that this would not likely have been averted by the use of an intraoperative shunt. The incidence of persisting postoperative transient ischemic events (occurring mostly in the immediate postoperative period) was $8 \%$, consistent with the reported literature. ${ }^{1,26,27}$ Hypertension was more common than hypotension in the immediate postoperative period, in contrast to the experience of others. ${ }^{28}$ It is not surprising that all the patients with cardiac complications had underlying atherosclerotic heart disease. The incidence of transient facial (mandibular branch) palsies in our series is somewhat higher than has been reported, ${ }^{29.30}$ probably reflecting the number of high bifurcations necessitating retraction at the angle of the jaw. Postoperative wound hematomata were related to raised blood pressure and severe coughing immediately after recovery from anaesthesia. None of the temporary complications prolonged the patients' hospital stay. Though this study was not controlled, we feel the hypervolemic hemodilution may have played a positive role in reducing the morbidity in our series. The overall results of this series of endarterectomies are comparable to those of other authors. $5,14.31 .32$
Table 4: Complications of Carotid Endarterectomy

Percentage of

(of 100 Procedures)

Mortality

$0 \%$

Major Morbidity

Operative Stroke

Minor Morbidity

Persistent Transient Cerebrovascular Events

Early Transient Ischaemia

(Within 30 days of surgery)

Late Transient Ischaemia

$7 \%$

$1 \%$

Cardiac Complications*

Angina Pectoris

Atrial Fibrillation

$5 \%$

Heart Block

Myocardial Infarct

Other Temporary Complications

Mandibular Palsy

Wound Hematomas

*All the patients had pre-existent ischaemic heart disease

\section{Discussion}

The age and sex distribution and the slight predominance of left-sided procedures in this series is in keeping with the literature. The clinical and angiographic indications for surgery in our series are also similar to those in most other series. Some authors ${ }^{13}$ have identified patients with contralateral complete occlusion as a group with a higher risk for stroke and suggest that they benefit from shunting, though this is not universally accepted. ${ }^{5.33}$

Persisting controversies surrounding carotid endarterectomy relate to the type of anaesthetic, the use of intraoperative vascular shunts and vein patch grafts, and the need for intraoperative monitoring of cerebral function. Though local and regional anaesthesia are still popular with some surgeons, ${ }^{34.35}$ most recent publications suggest a preference for general anaesthesia.

The use of shunts has been a major point of controversy. With exceptions, ${ }^{36.37}$ excellent surgical results have been obtained by groups using shunts routinely, ${ }^{6.11 .27 .38}$ selectively ${ }^{13.16,31}$ and not at all. ${ }^{5,7-9,12,14,15}$ The proponents of shunts claim they maintain cerebral perfusion, assist in the closure of arteriotomy, and are safe. However, the opponents of shunting point out that only rarely is hypoperfusion the cause of stroke, and that in most cases, strokes are embolic in nature. ${ }^{20,34.39}$ Shunts may also increase the risk of intimal flaps, dissection, luminal thrombosis, embolism (due to 'blind' insertion) and sometimes add to the technical difficulty of the procedure. The period of tolerance to cerebral ischemia in humans is unknown. However, occlusion of one middle cerebral artery for up to 2-3 hours has been demonstrated to be tolerated by the subhuman primate. ${ }^{40,41}$

Preoperative trial carotid occlusion (Matas test) has been used as a screening test to predict shunt requirement ${ }^{34.35}$ but this test has not been proved to be reliable and also carries a risk of embolic stroke. Intraoperative carotid back flow ${ }^{42}$ and stump pressure ${ }^{43}$ once used routinely to gauge collateral circulation, have been recently discredited. ${ }^{21.33 .44}$

Electroencephalography has been used extensively as a monitoring method, ${ }^{10.16,20,21}$ although Ferguson and others found in their experience that EEG is not entirely reliable..$^{9.15 .45 .46}$ 
More recently Ferguson, on the basis of further experience suggests shunting in a select group of patients with EEG and stump pressure changes. ${ }^{47}$ Decreased regional cerebral blood flow had been used as an indication for shunting but the exact cut off value has not been agreed upon ${ }^{16.48}$ and this is still a novel technique. The use of supraorbital photoplethysmography, ${ }^{19}$ cerebral perfusion pressure, ${ }^{22}$ and somatosensory evoked potentials ${ }^{17.18}$ for monitoring, await systematic and careful evaluation in larger groups of patients.

Patch grafting to improve patency has been carried out routinely in some cases, ${ }^{5,16,23,24}$ but has not been conclusively shown to improve the overall results of carotid endarterectomy. The routine use of patch grafts has to be weighed against the possibility of false aneurysm formation though a recent review suggests that the use of patch grafts may not significantly alter the incidence of this complication. ${ }^{49}$ The mild hypervolemic hemodilution used in this series may have played some role in optimizing cerebral oxygen delivery. This view is supported by recent evidence in favour of hypervolemic and isovolemic hemodilution in the management of stroke. ${ }^{50-52}$

\section{Conclusions}

For carotid endarterectomy to be an acceptable measure for stroke prophylaxis, the mortality and major morbidity of surgery have to be superior to the natural history and medical therapy. ${ }^{53-57}$ The beneficial effects of carotid endarterectomy have not been conclusively demonstrated, and at this point await the results of the large multicentre trials being undertaken. Current evidence suggests that cerebral function monitoring, intraoperative shunting and vein patch grafting are not essential to obtain acceptable results. We believe our series and those of others ${ }^{5,8,9,12,14}$ confirm this. We also believe that in order to evaluate the results of carotid endarterectomy satisfactorily, the preoperative risk status of patients has to be taken into consideration as the mortality and morbidity vary considerably amongst different risk groups. ${ }^{25}$ Careful patient selection along with the exclusion of patients with asymptomatic lesions, diffuse atherosclerotic disease and isolated vertebrobasilar disease as candidates for carotid endarterectomy, along with meticulous surgical technique are of great importance for a successful outcome. Hemorheologic manipulation may have played some positive role in our results.

\section{ACKNOWLEDGEMENTS}

The authors wish to thank Ms. D. Breckon, Ms. P. Frank and Ms. D. Henry for the help provided in the preparation of this manuscript, and the St. Boniface Hospital Records Department for providing the patient charts.

\section{REFERENCES}

1. Eastcott HHG, Pickering GW, Rob GC. Reconstruction of internal carotid artery in a patient with intermittent attacks of hemiplegia. Lancet 1954; 2: 994-996.

2. Cooley DA, Al-Naaman YD, Carton CA. Surgical treatment of arteriosclerotic occlusion of common carotid artery. J Neurosurg 1956; 13: 500-506

3. Dyken ML, Pokras R. The performance of endarterectomy for disease of the extracranial arteries of the head. Stroke 1977; 8: $565-568$

4. Hertzer NR, Beven EG. A retrospective comparison of the use of shunts during carotid endarterectomy. Surg Gyn Obst 1980; 151 : 81-84.

5. Ott DA, Cooley DA, Chapa L, et al. Carotid endarterectomy without temporary intraluminal shunt. Ann Surg 1980; 191(6): 708-714.

6. Schiro J, Mertz GH, Cannon JA, et al. Routine use of a shunt for carotid endarterectomy. Am J Surg 1981; 1942: 735-738.

7. Whitney DG, Kahn EM, Estes TE, et al. Carotid surgery without temporary indwelling shunt. Arch Surg 1980; 115: 1393-1399.

8. Bland JE, Lazar ML. Carotid endarterectomy without shunt. Neurosurgery $1981 ; 8(2)$ : 153-157.

9. Ferguson GG. Intraoperative monitoring and internal shunts: are they necessary in carotid endarterectomy? Stroke 1982; 13(3): 287-289.

10. Sundt TM. The ischaemic tolerance of neural tissue and the need for monitoring and selective shunting during carotid endarterectomy. Stroke 1983; 14(1): 93-98.

11. Browse NL, Ross-Russell R. Carotid endarterectomy and the Javid Shunt, the early results of 215 consecutive operations for transient ischaemic attacks. Br J Surg 1984; 71: 53-57.

12. Baker WH, Dorner DB, Barnes RW. Carotid endarterectomy - is an indwelling shunt necessary? Surgery 1977; 82(3): 321-326.

13. Baker WH. Diagnosis and treatment of carotid artery disease (2nd edition) 1985; Futura Publishing Co., New York.

14. Allen GS, Preziosi JJ. Carotid endarterectomy - a prospective study of its efficacy and safety. Medicine 1981; 4: 298-309.

15. Morawetz RB, Zeiger HE, McDowell HA. Correlation of CBF and EEG during carotid occlusion for carotid endarterectomy without shunting and neurologic outcome. Surgery 1984;96(2): 184-189.

16. Sundt JM, Piepgras DG, Bersold MJ. Monitoring and protecting cerebral function in neurovascular surgery. Rationale and techniques. Clin Neurosurg 1981; 29: 391-403.

17. Markand OM, Dilley RS, Moorthy SS, et al. Monitoring of somatosensory evoked responses during carotid endarterectomy. Arch Neurology 1984; 41: 375-378.

18. Gentili F, Lougheed WM, Yamashiro K, et al. The use of intraoperative monitoring of somatosensory evoked potentials to determine the need for temporary bypass shunting in endarterectomy. (Abst) Can J Neurol Sci May 1986; 13(2): 196.

19. Pearce HJ, Beccletti JJ, Brown HJ. Supraorbital photoplethystographic monitoring during carotid endarterectomy with the use of an interal shunt. Surgery 1980; 87(3): 339-342.

20. Rampil IJ, Correll JW, Rosenbaum SH, et al. Computerized EEG. Monitoring and carotid artery shunting. Neurosurgery 1983; 13(3): 276-279.

21. Ricotta JJ, Charlton MH, Deweese JA. Determining criteria for shunt placement during carotid endarterectomy - EEG and back pressure. Ann Surg 1983; 198(5): 642-645.

22. Archie JP. Feldman RW. Determinants of cerebral perfusion pressure during carotid endarterectomy. Arch Surg 1982;117:319-322.

23. Deriu GP, Ballotta $E$, Bonavinal $L$. The rationale for patch graft angioplasty after carotid endarterectomy - Early and Long Term Follow-up. Stroke 1984; 15(6): 972-979.

24. Little JR, Bryerton B, Furlan AJ. Saphenous vein patch grafts in carotid endarterectomy. J Neurosurg 1984; 61: 743-747.

25. Sundt TM, Sandok BS, Whisnant JP. Complications and preoperative assessment of risk. Mayo Clin Proc 1975; 50: 301-306.

26. Rosenthal D, Zeichner WD, Lamis PA, et al. Neurologic deficit after carotid endarterectomy. Pathogenesis and management. Surgery $1983 ; 94(5)$ : 776-780.

27. Lees CG, Hertzer NR. Postoperative stroke and late neurological complications after carotid endarterectomy. Arch Surg 1981; 116: 1561-1568.

28. Bove EL, Fry WJ, Gross WS, et al. Hypotension and hypertension as consequences of baroreceptor dysfunction following carotid endarterectomy. Surgery 1979; 85(6): 633-637.

29. Gianotta SL, Dicks RE, Kindt GW. Cranial nerve injury during carotid endarterectomy. Neurosurg 1981; 151: 513.

30. Dehn TCB, Taylor CW. Cranial and cervical nerve damage associated with carotid endarterectomy. Br J Surg 1983; 70: 365-368.

31. Whisnant JP, Sandok BA, Sundt TM. Carotid endarterectomy for unilateral carotid system transient cerebral ischaemia. Mayo Clin Proc 1983; 58: 171-175.

32. Ferguson GG. Extracranial carotid artery surgery. Clin Neurosurg 1981; 29: 563-574. 
33. Sachs SM, Fulenwider T, Smith RB, et al. Does contralateral carotid occlusion influence neurologic fate of carotid endarterectomy? Surgery 1984; 96(5): 839-844.

34. Kwaan JH, Peterson GJ, Connoly JE. Stump pressure, an unreliable guide for shunting during carotid endarterectomy. Arch Surg 1980; 115: 1083-1085.

35. Steed DL, Petzman AB, Grundy BL, et al. Causes of stroke in carotid endarterectomy. Surgery 1982; 92(4): 634-641.

36. Easton JD, Sherman DG. Stroke and mortality rate in carotid endarterectomy in 228 consecutive operations. Stroke 1977 ; 8: $565-568$.

37. Brett $T$, Thalinger $K$. The Practice of carotid endarterectomy in a large metropolitan area. Stroke 1984; 15(6): 950-956.

38. Slavish LG, Nicholas GG, Gee W. Review of a community hospital. Experience with carotid endarterectomy. Stroke 1984; 15(6): 956-959.

39. Boysen G. Cerebral hemodynamics in carotid surgery. Acta Neuro Scand 1973; 49 (Suppl. 52): 1-84

40. Sundt $T$, Michenfelder J. Focal transient cerebral ischemia in the Squirrel Monkey. Circ Res 1972; 30: 703-712.

41. Crowell RM, Olsson Y, Klatzo I, Ommaya A. Temporary occlusion of the middle cerebral artery in the monkey: clinical and pathological observations. Stroke 1970; 1: 439-448.

42. Littoy F, Hastok K, Mamdani M, et al. Factors influencing morbidity of carotid endarterectomy without a shunt. Am Surg 1984; 50(7): $350-353$.

43. Hays RJ, Levinson SA, Wylie EJ. Intraoperative measurement of carotid back flow pressure as a guide to operative management of carotid endarterectomy. Surgery 1972; 72(6): 953-960.

44. Hunter GC, Sieffert G, Malone JM, et al. The accuracy of carotid back pressure as an index of shunt requirement - a reappraisal. Stroke 1982; 13(3): 319-326.

45. Rosenthal D, Stanton PE, Lamis PA. Carotid endarterectomy the unrealiability of intraoperative monitoring in patients having had stroke and reversible ischaemic neurologic disease. Arch Surg 1981; 116: 1569-1575.

46. Green RM, Messick WJ, Ricotta JJ, et al. Benefits, shortcomings, and costs of EEG monitoring. Ann Surg 1985; 201(6): 785-792.

47. Ferguson GG. Carotid endarterectomy, to shunt or not to shunt? Arch Neurol 1986; 43(6): 615-616.

48. Rowed DW, Villaghy ML. Intraoperative rCBF during carotid endarterectomy. Can J Neurol Sci 1981; 8(3): 235-241.

49. Branch $\mathrm{CL} \mathrm{Jr}$, Davis $\mathrm{CH}$. False aneurysm complicating carotid endarterectomy. Neurosurgery 1986; 19(3): 421-425.

50. Wood JH, Kee DB. Hemorheology of the cerebral circulation with stroke. Stroke 1985; 16(5): 765-772.

51. Wood JH, Simeone FA, Fink EA, et al. Hypervolemic hemodilution in experimental focal cerebral ischemia: elevation of cardiac output, regional cortical blood flow and ICP after intravascular volume expansion with low molecular weight Dextran. J Neurosurg 1983; 59: 500-509.

52. Strand T, Asplund K, Eriksson S, et al. A randomized controlled trial of hemodilution therapy in acute ischemic stroke. Stroke 1984; 15: 980-989.

53. Chambers BR, Norris JW. The case against surgery for asymptomatic carotid stenosis. Stroke 1984; 15(6): 964-967.

54. Yatsu FM, Hart RG. Asymptomatic carotid bruit and stenosis: a reappraisal. Stroke 1985; 14(2): 301-304.

55. Durward QJ, Ferguson GG, Barr HWK. The natural history of asymptomatic carotid bifurcation plaques. Stroke 1982; 13(4): 459-464.

56. Wolf P, Kannel WB, Sorlie P, et al. Asymptomatic carotid bruit and risk of stroke: The Framingham Study. JAMA 1981; 245 1442-1445.

57. Heyman A, Wilkinson WE, Heyden S, et al. Risk of stroke in asymptomatic persons with cervical arterial bruits: a population study in Evans County, Georgia. NEJ Med 1980; 302: 838-841. 